\title{
Near-death experiences in non-life-threatening events and coma of different etiologies
}

\author{
Vanessa Charland-Verville ${ }^{1}$, Jean-Pierre Jourdan ${ }^{2}$, Marie Thonnard ${ }^{1}$, Didier Ledoux ${ }^{1}$, \\ Anne-Francoise Donneau ${ }^{3}$, Etienne Quertemont ${ }^{4}$ and Steven Laureys ${ }^{1 *}$ \\ ${ }^{1}$ Coma Science Group, Cyclotron Research Center and Neurology Department, University and University Hospital of Liège, Liège, Belgium \\ 2 International Association For Near Death Studies, Oraison, France \\ ${ }^{3}$ Department of Public Health, University of Liège, Liège, Belgium \\ ${ }^{4}$ Department of Psychology, Cognitive and Behavioral Neurosciences Center, University of Liège, Liège, Belgium
}

Edited by:

Enrico Facco, University of Padua, Italy

\section{Reviewed by:}

Rüdiger Ilg, Technische Universität München, Germany

Christopher Charles French,

Goldsmiths, University of

London, UK

${ }^{*}$ Correspondence:

Steven Laureys, Coma Science

Group, Cyclotron Research Center and Neurology Department,

University and University Hospital of

Liège, Allée du 6 août no 8, Sart

Tilman B30, 4000 Liège, Belgium

e-mail: steven.laureys@ulg.ac.be
Background: Near death experiences (NDEs) are increasingly being reported as a clearly identifiable physiological and psychological reality of clinical significance. However, the definition and causes of the phenomenon as well as the identification of NDE experiencers is still a matter of debate. To date, the most widely used standardized tool to identify and characterize NDEs in research is the Greyson NDE scale. Using this scale, retrospective and prospective studies have been trying to estimate their incidence in various populations but few studies have attempted to associate the experiences' intensity and content to etiology.

Methods: This retrospective investigation assessed the intensity and the most frequently recounted features of self-reported NDEs after a non-life-threatening event (i.e., "NDE-like" experience) or after a pathological coma (i.e., "real NDE") and according to the etiology of the acute brain insult. We also compared our retrospectively acquired data in anoxic coma with historical data from the published literature on prospective post-anoxic studies using the Greyson NDE scale.

Results: From our 190 reports who met the criteria for NDE (i.e., Greyson NDE scale total score $>7 / 32$ ), intensity (i.e., Greyson NDE scale total score) and content (i.e., Greyson NDE scale features) did not differ between "NDE-like" $(n=50)$ and "real NDE" ( $n=140)$ groups, nor within the "real NDE" group depending on the cause of coma (anoxic/traumatic/other). The most frequently reported feature was peacefulness (89-93\%). Only 2 patients (1\%) recounted a negative experience. The overall NDE core features' frequencies were higher in our retrospective anoxic cohort when compared to historical published prospective data.

Conclusions: It appears that "real NDEs" after coma of different etiologies are similar to "NDE-like" experiences occurring after non-life threatening events. Subjects reporting NDEs retrospectively tend to have experienced a different content compared to the prospective experiencers.

Keywords: Near-death experiences, Greyson NDE scale, coma, cardiac arrest, traumatic brain injury, memory, non-life threatening events

\section{INTRODUCTION}

The expression "Near-Death Experience" (NDE) was first formulated in the nineteenth century when a Swiss geologist collected testimonies from his fellow climbers and himself after making a fall in the Alps (Heim, 1891). Some decades later, Moody (1975) popularized the expression through his best seller "Life after life" in which he defined NDEs as "any conscious perceptual experience occurring in individuals pronounced clinically dead or who came very close to physical death" and drew a list of the most frequently recounted features by individuals who had survived near-fatal incidents. These NDE features included:

Abbreviations: Near-Death Experiences, NDEs; Near-Death Experiencers, NDErs; Weighted Core Experience Index, WCEI. overwhelming feelings of peacefulness and well-being; painlessness; the impression of being located outside one's physical body; the impression of drifting through a dark environment that looks like a tunnel; the sight of a brilliant light and the feeling of being surrounded by it; the impression of discovering another world described as idyllic; the feeling of a close presence; the encounter and communication with spirits or deceased relatives or experiencing a "life review" (Moody, 1975). More recently, NDEs have been defined as a "profound psychological event including transcendental and mystical elements, typically occurring to individuals close to death or in situations of intense physical or emotional danger" (Greyson, 2000).

Empirical studies of NDEs have mostly been conducted in patients with life threatening situations such as cardiac arrest 
(Parnia et al., 2001; van Lommel et al., 2001; Schwaninger et al., 2002; Greyson, 2003a; French, 2005; Klemenc-Ketis et al., 2010) or (albeit more rarely) in patients with severe traumatic brain injury (Hou et al., 2013). To the best of our knowledge, no study has formally compared the influence of the cause of coma to the intensity or content of the NDE. Unlike these "real NDEs" associated with "real" closeness to death or coma, possible NDEs or "NDE-like" experiences have also been reported in situations where there was no genuine threat to the individuals' life. Only a few studies have assessed "NDE-like" phenomena in non-life threatening situations (Gabbard et al., 1981; Owens et al., 1990; Gabbard and Twemlow, 1991; Kelly, 2001; Facco and Agrillo, 2012). Such accounts have also been reported in epileptic patients (Hoepner et al., 2013), syncope (Lempert et al., 1994), intense grief and anxiety (Kelly, 2001), Cotard's syndrome (McKay and Cipolotti, 2007; Charland-Verville et al., 2013) and during meditative state (Beauregard et al., 2009). It remains unclear whether NDEs occurring in life-threatening or non-life threatening situations differ in intensity or core features. In addition to the ill-described relation between the NDE and the precipitating factor, the reliability of NDEs accounts also remains controversial (Martens, 1994; French, 2001). For instance, it seems that fewer cases of NDEs are recounted by individuals interviewed prospectively than when the interviews are conducted retrospectively (Mobbs and Watt, 2011). On the other hand, it has been shown that reports of NDEs were not modified over time even 20 years after the original account (Greyson, 2007).

Using the Greyson NDE scale (Greyson, 1983), the present retrospective study aimed at (1) exploring the NDE intensity and content in "NDE-like" accounts following non-life-threatening events vs. "real NDE" following coma; (2) comparing the "real NDE" characteristics according to the etiology of the brain damage (anoxic, traumatic or other) and (3) comparing our retrospectively obtained data in anoxic coma to historical previously published prospectively collected post-anoxic NDEs.

\section{MATERIALS AND METHODS}

Participants were recruited via the website, publications and appearances in local media of the International Association for Near-Death Studies (IANDS France and IANDS Flanders) and the Coma Science Group (University of Liège, Belgium). Written, email or telephone completion of an anonymous questionnaire was voluntary and taken as consent for participation in the survey. The study was approved by the ethics committee of the Faculty of Medicine of the University of Liège. The questionnaire included items about demographic (age at NDE, gender) and clinical data (time since NDE, presence of life threatening event, presence of acute coma (i.e., a period of unconsciousness $>1$ h; Posner et al., 2007)), etiology of coma (anoxic/traumatic/other) and a standardized characterization of the NDE using the Greyson NDE scale (Greyson, 1983). The Greyson NDE scale is a validated (Lange et al., 2004) 16-item multiple-choice tool used to quantify the intensity of the NDE (i.e., total score ranging from 0 to 32) and to assess core content components of $16 \mathrm{NDE}$ features. For each item, the scores are arranged on an ordinal scale ranging from 0 to 2 (i.e., $0=$ "not present," $1=$ "mildly or ambiguously present," and 2 = "definitively present"; Greyson, 1983; Lange et al., 2004). For statistical analyses, a feature was considered present when participants scored an item as 1 or 2 (Greyson, 1983, 2003a). Participants whose experience did not meet the accepted criteria of NDE (i.e., Greyson total score <7; Greyson, 1983) were excluded from the present analysis.

First, we verified that "NDE-like" and "real NDE" groups and the 3 coma etiologies of the "real NDE" group (i.e., anoxic/traumatic/other) were matched for gender, age at NDE, and interval since NDE. A Pearson's chi square test with contingency tables was performed to compare the gender ratios between the "NDE-like" and "real NDE" groups as well as between the 3 coma etiologies (i.e., anoxic/traumatic/other) of the "real NDE" group. A Student's $t$-test was performed to compare age at NDE and time since NDE between the "NDE-like" and "real NDE" groups and a One-Way ANOVA was performed to compare the age at NDE and the time since NDE within the coma 3 etiologies of the "real NDE" group. Next, we looked for differences in NDE overall intensity (i.e., total NDE scale's scores) between "NDE-like" and "real NDE" groups' using Student's $t$-testing. A Pearson's chi square test with contingency tables was performed to assess for possible discrepancies between the reported features frequencies in "NDE-like" and "real NDE" groups. A One-Way ANOVA was performed in order to test for differences in intensity within the "real NDE" group depending on the etiology of coma. A Pearson's chi square test with contingency tables was performed to assess for possible discrepancies between the reported features frequencies according to the coma etiology. Finally, the present retrospective data in anoxic coma were compared with a historical dataset of prospective data taken from the published literature on NDE after anoxic coma (Parnia et al., 2001; Schwaninger et al., 2002; Greyson, 2003a). For each feature of the Greyson NDE scale, the proportions of positive answers between retrospective and prospective studies were compared by the classical chi-squared test for contingency tables or by the Fisher exact test. Further, the overall comparison between the two study groups was made by the Generalized Estimating Equations Approach (GEE), which accounts for percentage variability within NDE features.

\section{RESULTS}

Results were considered to be significant at the 5\% critical level $(p<0.05)$ and were expressed as mean \pm standard deviation (SD) for quantitative variables and as counts and proportions (\%) for categorical variables. Data analysis was carried out using SAS (version 9.3 for Windows) statistical package. Out of the 215 selfreported NDEs, 25 did not meet the criteria for NDE (i.e., NDE scale total score <7/32) (Greyson, 1983) and were excluded from the current study. Table 1 shows the demographic characteristics of the different groups constituting the retrospective study cohort ( $n=190 ; 104$ females (55\%); age at NDE $32 \pm 14$ year; time since NDE $24 \pm 15$ year). The "NDE-like" group $(n=50)$ included NDEs occurring following a non-life-threatening event such as during sleep $(n=13)$, syncope $(n=11)$, meditation $(n=5)$, drugs and alcohol consumption $(n=3)$, or other non-life threatening situations $(n=18)$. The "real NDE" group $(n=140)$ was divided according to the etiology of the coma: "anoxic" (e.g., cardiac arrest, near-drowning, $n=45$ ); "traumatic" (e.g., motor vehicle accident, falls, $n=30$ ) and "other" (i.e., non-traumatic events such as an exacerbation of on-going illness, complication during surgery, $n=65$ ). There were no significant differences in 
gender, age at time of NDE and interval since NDE between the "NDE-like" and "real NDE" groups and within the "real NDE" groups depending on etiology.

Intensity (i.e., Greyson NDE scale total score) and content (i.e., NDE scale features) of reported NDEs did not differ between "NDE-like" and "real NDE" groups nor within the "real NDE" group depending on the cause of coma (anoxic/traumatic/other) (see Table 2). For all study groups, the most frequently reported core NDE feature was the feeling of peacefulness for all study groups (frequency range: 89-93\%). Only 18/190 (10\%) did not experience positive emotions such as peacefulness, happiness or joy; 2 of whom explicitly recounted a negative experience (both following a life threatening event; 2 females, aged 31 and 41 who were comatose due to a complication after childbirth and surgery, respectively). Finally, the overall NDE core features' frequencies were significantly higher in our retrospective anoxic cohort $(n=45 ; 20$ females $44 \%)$ when compared to historical published prospective data (Parnia et al., 2001; Schwaninger et al., 2002; Greyson, 2003a) obtained after anoxic coma $(p<0.0001)$. An altered time perception, the feeling of harmony and unity, the sudden understanding of everything, heightened senses were more frequently reported in the current retrospective dataset on post-anoxic NDE while encounters with deceased or religious spirits were more frequently reported in previous prospective studies on post-anoxic NDE (see Table 3 ).

Table 1 | NDErs demographic characteristics $(N=190)$.

\begin{tabular}{|c|c|c|c|c|c|c|c|}
\hline \multirow[t]{2}{*}{ Demographics } & \multirow{2}{*}{$\begin{array}{c}\text { "NDE-like" } \\
n=50\end{array}$} & \multirow{2}{*}{$\begin{array}{c}\text { "Real NDE" } \\
n=140\end{array}$} & \multirow[t]{2}{*}{$p$} & \multicolumn{3}{|c|}{ “Real NDE” etiologies } & \multirow[t]{2}{*}{$\boldsymbol{p}$} \\
\hline & & & & $\begin{array}{c}\text { Anoxic } \\
n=45\end{array}$ & $\begin{array}{c}\text { Traumatic } \\
n=30\end{array}$ & $\begin{array}{l}\text { Other } \\
n=65\end{array}$ & \\
\hline Gender-female & $25(50 \%)$ & $79(57 \%)$ & 0.43 & $20(44 \%)$ & $15(50 \%)$ & $44(68 \%)$ & 0.20 \\
\hline Age at NDE & $31 \pm 11$ & $32 \pm 15$ & 0.76 & $35 \pm 16$ & $29 \pm 11$ & $31 \pm 17$ & 0.26 \\
\hline (Mean in years $\pm S D$, range) & $4-60$ & $3-76$ & & 8-64 & $6-50$ & 3-76 & \\
\hline Time since NDE & $23 \pm 16$ & $24 \pm 15$ & 0.82 & $20 \pm 14$ & $26 \pm 11$ & $25 \pm 17$ & 0.10 \\
\hline (Mean in years $\pm S D$, range) & $0.13-66$ & $0.15-75$ & & $0.15-50$ & $3-43$ & $1-75$ & \\
\hline
\end{tabular}

Table 2 | NDE intensity (Greyson Scale total score) and content (core features) reported in "NDE-like" and "real NDE" groups-by decreasing order of frequency according to the "real NDE" group (significance level $p<0.05$ ).

\begin{tabular}{|c|c|c|c|c|c|c|c|}
\hline NDE Scale features & $\begin{array}{l}\text { “NDE-like" } \\
n=50(\%)\end{array}$ & $\begin{array}{c}\text { "Real NDE" } \\
n=140(\%)\end{array}$ & $\boldsymbol{p}$ & \multicolumn{3}{|c|}{ “Real NDE” etiologies } & $\boldsymbol{p}$ \\
\hline "Did you have a feeling of peace or pleasantness?" & $45(90)$ & $127(91)$ & 0.88 & $40(89)$ & $28(93)$ & $59(91)$ & 0.81 \\
\hline "Did you feel separated from your body?" & $37(74)$ & $111(79)$ & 0.44 & $36(80)$ & $24(80)$ & $51(79)$ & 0.98 \\
\hline $\begin{array}{l}\text { "Did you see, or feel surrounded by, a brilliant } \\
\text { light?" }\end{array}$ & $42(84)$ & $106(76)$ & 0.23 & $32(71)$ & $20(67)$ & $54(83)$ & 0.15 \\
\hline $\begin{array}{l}\text { "Did you seem to enter some other, unearthly } \\
\text { world?" }\end{array}$ & $35(70)$ & $101(72)$ & 0.77 & $33(73)$ & $21(70)$ & $47(72)$ & 0.95 \\
\hline "Did you have a feeling of joy?" & $37(74)$ & $98(70)$ & 0.59 & $32(71)$ & $18(60)$ & $48(74)$ & 0.38 \\
\hline $\begin{array}{l}\text { "Did you feel a sense of harmony or unity with the } \\
\text { universe?" }\end{array}$ & $39(78)$ & $96(69)$ & 0.21 & $33(73)$ & $21(70)$ & $42(65)$ & 0.61 \\
\hline $\begin{array}{l}\text { "Did you seem to encounter a mystical being or } \\
\text { presence, or hear an unidentifiable voice?" }\end{array}$ & $29(58)$ & $71(51)$ & 0.38 & $20(44)$ & $12(40)$ & $39(60)$ & 0.12 \\
\hline "Were your thoughts speeded up?" & $20(40)$ & $62(44)$ & 0.60 & $23(51)$ & $15(50)$ & $24(37)$ & 0.26 \\
\hline "Did you see deceased or religious spirits?" & $17(34)$ & $54(39)$ & 0.57 & $12(27)$ & $9(30)$ & $33(51)$ & 0.063 \\
\hline $\begin{array}{l}\text { "Did you seem to be aware of things going on } \\
\text { elsewhere, as if by ESP?" }\end{array}$ & $14(28)$ & $47(34)$ & 0.50 & $10(22)$ & $9(30)$ & $28(43)$ & 0.067 \\
\hline "Did scenes from your past come back to you?" & $9(18)$ & $37(26)$ & 0.23 & $11(24)$ & $11(37)$ & $15(23)$ & 0.35 \\
\hline "Did scenes from the future come to you?" & $9(18)$ & $26(19)$ & 0.93 & $8(18)$ & $5(17)$ & $13(20)$ & 0.92 \\
\hline Total score (mean $\pm S D$, range) & $17 \pm 7,7-30$ & $16 \pm 6,7-30$ & 0.10 & $15 \pm 6,7-28$ & $16 \pm 6,7-26$ & $16 \pm 6,7-30$ & 0.29 \\
\hline
\end{tabular}




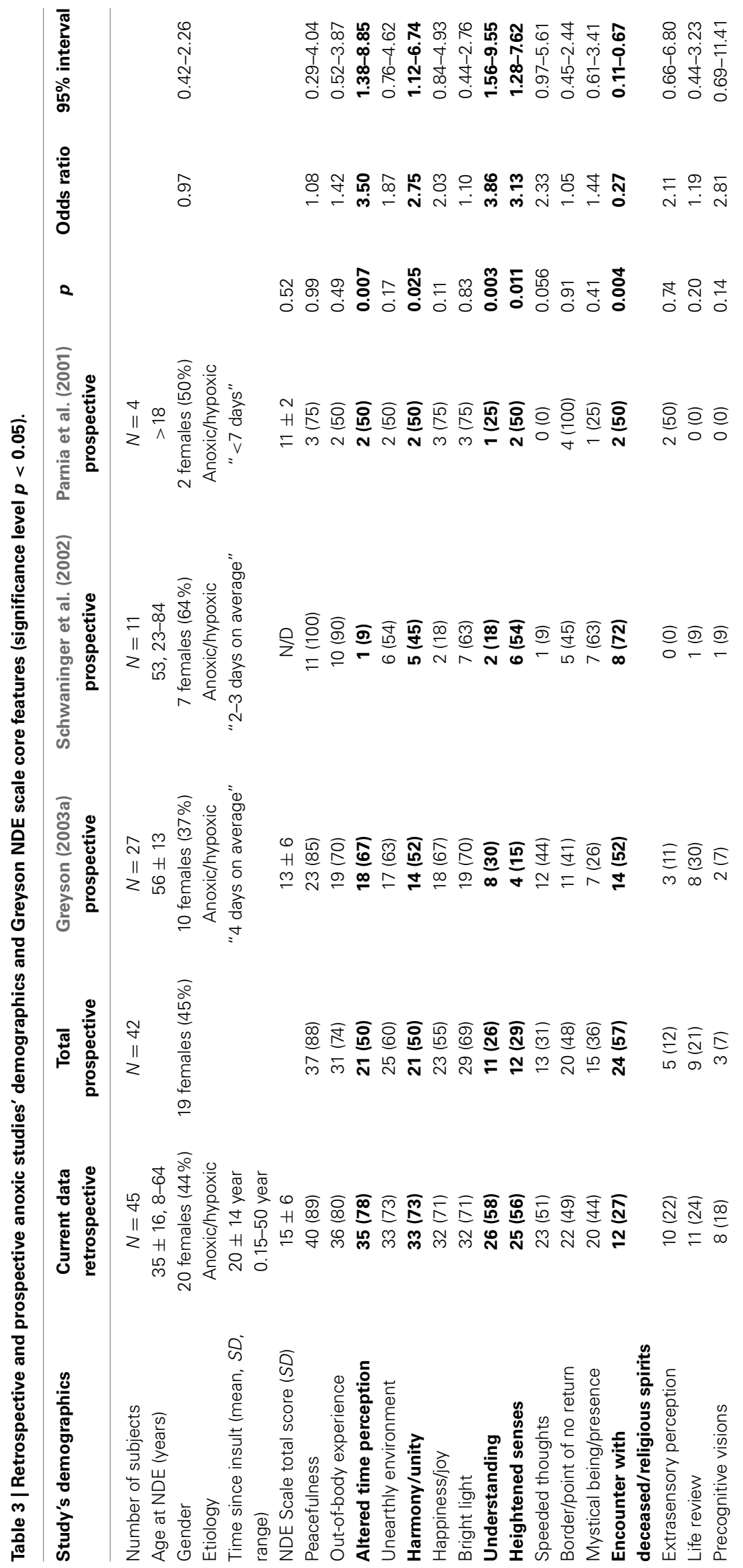




\section{DISCUSSION}

We here used the Greyson NDE scale (Greyson, 1983) to retrospectively assess the characteristics of 190 self-reported NDEs precipitated by a non-life threatening event or coma. The Greyson NDE scale is a widely used and validated tool to assess the intensity and content of NDEs (Greyson, 1990, 2003a,b; Parnia et al., 2001; Schwaninger et al., 2002; Nelson et al., 2006; Lai et al., 2007; Klemenc-Ketis et al., 2010; Hoepner et al., 2013; Hou et al., 2013) and, in contrast to the Weighted Core Experience Index (WCEI; Ring, 1980), provides a cut-off score permitting a standardized identification of NDE experiencers (NDErs). As for other retrospective studies on NDEs (Greyson, 1990; Lai et al., 2007), the interval between the age at study enrollment (mean age $56 \pm 13$ year) and the occurrence of the NDE (mean age $32 \pm 15$ year) was several decades (mean $24 \pm 15$ year). Our study sample did not show a significantly higher proportion of female NDErs. In the "real NDE" coma-survival group, the most frequently reported features (i.e., occurring $>75 \%$ ) include the feeling of peacefulness, out-of-body-experiences, seeing a bright light, alerted time perception. Conversely, precognitive visions (e.g., seeing the future) and the experience of life review were among the least frequently reported core features (i.e., occurring $<30 \%$ ). These results corroborate previous reports on NDE studies using the Greyson NDE scale (Greyson, 1990, 2003a; Parnia et al., 2001; Schwaninger et al., 2002; Nelson et al., 2006; Lai et al., 2007) or the WCEI (van Lommel et al., 2001). According to the etiology of coma, a recent prospective study reporting interview transcripts of post-traumatic coma survivors with a NDE revealed that the most frequently reported elements were the sight of an intense light, feelings of astonishment, pleasure and sense of helplessness (Hou et al., 2013). Although the well-being component is one of the most often reported features in classical NDEs, it is important to note that distressing or hellish experiences can also occur. In line with previous estimations (Lindley et al., 1981; Gallup and Proctor, 1982; Sabom, 1982; Ring, 1984), we recorded an incidence of $1.4 \%(2 / 140)$ of our "real NDE" group that reported to have had a negative NDE.

Some authors have tried to explain the phenomenology of NDE by diverse physiological explanations such as anoxic brain damage (Rodin, 1980; Blackmore, 1993; Greyson, 1998; Els et al., 2004; Woerlee, 2005; Ammermann et al., 2007), hypoxia (Lempert et al., 1994), hypercapnia (Klemenc-Ketis et al., 2010), abnormal temporal lobe dysfunctions (Blanke et al., 2002, 2004; Britton and Bootzin, 2004; Blanke and Mohr, 2005; Arzy et al., 2006; Hoepner et al., 2013), administration of sedatives (Cobcroft and Forsdick, 1993; Osterman et al., 2001; Lopez et al., 2006), or sleep abnormalities (Nelson et al., 2006, 2007). However, to the best of our knowledge, previous studies on NDE after coma have not aimed at identifying differences in NDE characteristics depending on the etiology (i.e., traumatic, non-traumatic anoxic or non-traumatic other acute brain insults) of the prolonged loss of consciousness. Despite our relatively large sample size, our analyses failed to show a significant difference on NDE intensity or content between these different causes of coma (matched for age, gender and interval since NDE). In the current study sample, we did not observe a significant difference in NDE intensity or core feature frequency when comparing "real NDE" after coma to "NDE-like" events occurring after non-life-threatening events.
Some authors have argued that the strong belief or fear of dying might be the key determinant for triggering a NDE (Gabbard et al., 1981; Stevenson et al., 1989-1990; Gabbard and Twemlow, 1991) independently of the actual organic brain damage.

Features of a NDE occurring during situations that are not life threatening and that are not perceived as such like during sleep or a meditative state cannot be explained by the expectancy of an incoming death. Individuals put in apparently life-threatening situations (e.g., involved in various accidents or undergoing surgery) might think the worst could happen even though the real medical situations result in none or minor brain insults (Gabbard and Twemlow, 1991; Facco and Agrillo, 2012). Likewise, the first historical reports of NDE testimonies obtained from Alpine mountain climbers who had suffered a non-fatal fall also illustrate the role of psychological reactions to a perceived life-threatening event in the generation of NDEs (Heim, 1891). Owens et al. (1990) reported that both "NDE like" and "real NDEs" showed a comparable phenomenology including positive emotions, outof-body experiences, tunnel-like perceptions and memory flashbacks. In contrast to our findings they reported that NDErs who had been in a life threatening condition (i.e., "real NDE") tended to more frequently report seeing a bright light and experiencing enhanced cognitive functions (e.g., speeded thoughts and sense of understanding). Gabbard and Twemlow (1991), on the other hand, observed that individuals who self-reported a "close brush with death," as compared to those who did not, experienced more out-of-body experiences. It is difficult to compare these findings with the present data because both previous studies did not employ a standardized scale for the characterization of the NDE. Using the Greyson NDE scale, Kelly (2001) reported that individuals who were close to death more often encountered deceased relatives during the NDE. Furthermore, the reports of those encounters were more frequent when the precipitating factor was a traumatic brain injury or a cardiac arrest than when the NDE was precipitated by a complication during childbirth or surgery (Kelly, 2001). The fact that we did not observe such differences in our current sample could be explained by the heterogeneity of the investigated samples' etiologies as well as the ill-defined nature of the non-life-threatening conditions.

It is important to stress that our study has a number of methodological limitations. Retrospective recruitment of selfreported NDEs may not represent a reliable sample of the NDErs population since they might have greater interest in and knowledge of NDEs. In addition to the probable sample-bias related to the recruitment of medically uncontrolled NDEs, the interval between the occurrence of the NDE and the age at study enrollment was several decades_-similar to other retrospective surveys (Greyson, 1990; Lai et al., 2007). We therefore compared our retrospective data with prospectively obtained published datasets. In order to reduce the possible confound of heterogeneity in etiology and NDE characterization we have chosen to compare our retrospective anoxic coma group with results from published prospective NDE studies on anoxic coma also using the Greyson NDE scale (Parnia et al., 2001; Schwaninger et al., 2002; Greyson, 2003a). Our comparison identified a higher overall frequency of NDE core features occurrence in our retrospective sample (Table 3). Similarly, a recent review by Mobbs and Watt (2011) also points to a higher incidence of NDEs in retrospective as 
compared to prospective studies. These findings could be related to the claim of some authors that NDE reports might suffer from memory reconstructions (French, 2001; Martens, 1994). However, Greyson (2007) has reported that the memories of NDE core features did not modify over time. Moreover, our data suggest that encounters with deceased or religious spirits are more frequently reported prospectively. It should be stressed that any statistical comparison of different study designs (retrovs. prospective) is methodologically problematic because of small sample sizes, high variability and sampling error. Consequently, it is difficult to assign appropriate weights reflecting the relative "value" of the information provided in each study. However, our findings on differences between retrospective and prospective post-anoxic NDE reports seem to be confirmed when extended to other etiologies as illustrated in Figure 1. A visual comparison of the weighted ratios of core NDE features calculated from four retrospective studies (Greyson, 1990; Nelson et al., 2006; Lai et al., 2007) (total $n=429$; including the present dataset) and four prospective studies (Parnia et al., 2001; Schwaninger et al., 2002; Greyson, 2003a; Hoepner et al., 2013) (total $n=47$ ), all using the Greyson NDE scale, illustrates that all items (with the exception of encounters with deceased or spirits) seem more frequently reported retrospectively.

It seems that NDEs cannot be explained solely by the closeness to death or by the etiology of the precipitating factor. The question whether the NDEs' extraordinary features can be fully explained by cerebral activity is still a matter of debate and a challenge awaiting the neuroscientific analysis of this phenomenon is to identify the neural correlates of such a physiologically real yet unexplained cognitive experience. Studying NDEs continues to represent a methodological challenge and investigators must rely on testimonies and indirect ways to understand the brain mechanisms associated with such an experience. When we compared our medically uncontrolled retrospectively obtained results to historical data from controlled prospective trials, several core features seemed to be more frequently reported when retrospectively collected (i.e., altered time perception, harmony, understanding and heightened senses). In line with our findings and as previously stressed (Facco and Agrillo, 2012), NDE research might benefit from the introduction of a new terminology to account for "NDE-like" experiences. In addition to the use of closed NDE questionnaires, which only leave restricted choices for describing the experience, future studies should employ statistical examination of freely expressed NDEs narratives using automated user-independent qualitative analyses of their content (Hou et al., 2013), taking into account the clinical data and study design.

\section{AUTHOR CONTRIBUTIONS}

Vanessa Charland-Verville and Steven Laureys designed the study, wrote the manuscript and conducted the analyses. Vanessa Charland-Verville, Jean-Pierre Jourdan, Marie Thonnard, Steven Laureys, collected all data and contributed to the final manuscript. Anne-Francoise Donneau, Didier Ledoux and Etienne Quertemont contributed to the analyses and to the revision of the final manuscript. Jean-Pierre Jourdan and Steven

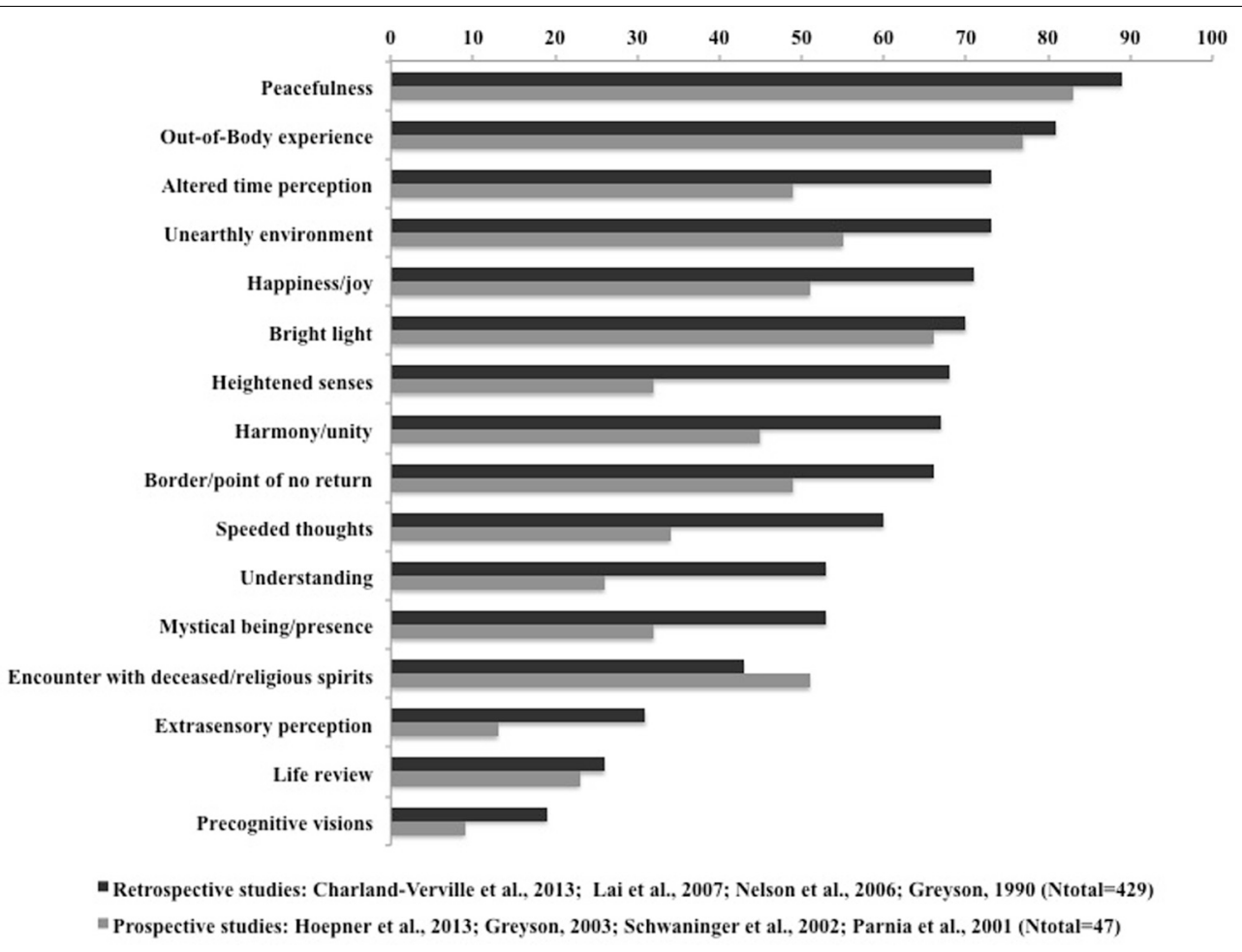

FIGURE 1 | Frequency of NDE features in retrospective and prospective studies (all etiologies) according to the Greyson NDE scale by decreasing order according to the retrospective data. 
Laureys provided conceptual input and contributed to the final manuscript. All authors approved the final version of the manuscript.

\section{ACKNOWLEDGMENTS}

The authors thank Guy Vander Linden from the IANDS Flanders (www.bijnadoodervaring.be) for their help in recruiting NDE testimonies. This research was supported by the European Commission (European ICT Programme Projects FP7-247919 DECODER), the Belgian National Funds for Scientific Research (FNRS), the Tinnitus Prize 2011 (FNRS 9.4501.12), FEDER structural fund RADIOMED-930549, Fonds Léon Fredericq, the James McDonnell Foundation, the French Speaking Community Concerted Research Action and the University and University Hospital of Liège. The funding sources are not liable for any use that may be made of the information contained therein. The funders had no role in study design, data collection and analysis, decision to publish, or preparation of the manuscript.

\section{REFERENCES}

Ammermann, H., Kassubek, J., Lotze, M., Gut, E., Kaps, M., Schmidt, J., et al. (2007). MRI brain lesion patterns in patients in anoxia-induced vegetative state. J. Neurol. Sci., 260, 65-70. doi: 10.1016/j.jns.2007.03.026

Arzy, S., Seeck, M., Ortigue, S., Spinelli, L., and Blanke, O. (2006). Induction of an illusory shadow person. Nature 443, 287-287. doi: 10.1038/443287a

Beauregard, M., Courtemanche, J., and Paquette, V. (2009). Brain activity in neardeath experiencers during a meditative state. Resuscitation 80, 1006-1010. doi: 10.1016/j.resuscitation.2009.05.006

Blackmore, S. (1993). Dying to Live: Science and Near-Death Experience. London: Grafton.

Blanke, O., Landis, T., Spinelli, L., and Seeck, M. (2004). Out-of-body experience and autoscopy of neurological origin. Brain 127(Pt 2), 243-258. doi: 10.1093/brain/awh040

Blanke, O., and Mohr, C. (2005). Out-of-body experience, heautoscopy, and autoscopic hallucination of neurological origin Implications for neurocognitive mechanisms of corporeal awareness and self-consciousness. Brain Res. Brain Res. Rev. 50, 184-199. doi: 10.1016/j.brainresrev.2005.05.008

Blanke, O., Ortigue, S., Landis, T., and Seeck, M. (2002). Stimulating illusory ownbody perceptions. Nature 419, 269-270. doi: 10.1038/419269a

Britton, W. B., and Bootzin, R. R. (2004). Near-death experiences and the temporal lobe. Psychol. Sci. 15, 254-258. doi: 10.1111/j.0956-7976.2004.00661.x

Charland-Verville, V., Bruno, M. A., Bahri, M. A., Demertzi, A., Desseilles, M., Chatelle, C., et al. (2013). Brain dead yet mind alive: a positron emission tomography case study of brain metabolism in Cotard's syndrome. Cortex 49, 1997-1999. doi: 10.1016/j.cortex.2013.03.003

Cobcroft, M. D., and Forsdick, C. (1993). Awareness under anaesthesia: the patients' point of view. Anaesth. Intensive Care 21, 837-843.

Els, T., Kassubek, J., Kubalek, R., and Klisch, J. (2004). Diffusion-weighted MRI during early global cerebral hypoxia: a predictor for clinical outcome? Acta Neurol. Scand. 110, 361-367. doi: 10.1111/j.1600-0404.2004.00342.x

Facco, E., and Agrillo, C. (2012). Near-death-like experiences without lifethreatening conditions or brain disorders: a hypothesis from a case report. Front. Psychol. 3:490. doi: 10.3389/fpsyg.2012.00490

French, C. C. (2001). Dying to know the truth: visions of a dying brain, or false memories? Lancet 358, 2010-2011. doi: 10.1016/S0140-6736(01) 07133-1

French, C. C. (2005). "Near-death experiences in cardiac arrest survivors," in Progress in Brain Research, Vol. 150, ed S. Laureys (Amsterdam: Elsevier), 351-367.

Gabbard, G. O., Twemlow, S. W., and Jones, F. C. (1981). Do "near death experiences" occur only near death? J. Nerv. Ment. Dis. 169, 374-377. doi: 10.1097/00005053-198106000-00006

Gabbard, G., and Twemlow, S. (1991). Do "near-death experiences" occur only near-death?- Revisited. J. Near Death Stud. 10, 41-47. doi: 10.1007/BF01073295
Gallup, G., and Proctor, W. (1982). Adventures in Immortality: a Look Beyond the Threshold of Death. New York, NY: McGraw-Hill.

Greyson, B. (1983). The near-death experience scale. Construction, reliability, and validity. J. Nerv. Ment. Dis. 171, 369-375. doi: 10.1097/00005053-19830600000007

Greyson, B. (1990). Near-death encounters with and without near-death experiences: comparative NDE Scale profiles. J. Near Death Stud. 8, 151-161. doi: 10.1007/BF01074000

Greyson, B. (1998). Biological aspects of near-death experiences. Perspect. Biol. Med. 42, 14-32.

Greyson, B. (2000). "Near-death experiences," in Varieties of Anomalous Experiences: Examining the Scientific Evidence, eds E. Cardena, S. Lynn, and S. Krippner (Washigton, DC: American Psychological Association), 315-352. doi: 10.1037/10371-010

Greyson, B. (2003a). Incidence and correlates of near-death experiences in a cardiac care unit. Gen. Hosp. Psychiatry 25, 269-276. doi: 10.1016/S01638343(03)00042-2

Greyson, B. (2003b). Near-death experiences in a psychiatric outpatient clinic population. Psychiatr. Serv. 54, 1649-1651. doi: 10.1176/appi.ps.54.12.1649

Greyson, B. (2007). Consistency of near-death experience accounts over two decades: are reports embellished over time? Resuscitation 73, 407-411. doi: 10.1016/j.resuscitation.2006.10.013

Heim, A. (1891). Notizen uber den Tod durch Absturtz. Jahrbuch des schweizer. Alpenclub 27, 327-337.

Hoepner, R., Labudda, K., May, T. W., Schoendienst, M., Woermann, F. G., Bien, C. G., et al. (2013). Ictal autoscopic phenomena and near death experiences: a study of five patients with ictal autoscopies. J. Neurol. 260, 742-749. doi: 10.1007/s00415-012-6689-x

Hou, Y., Huang, Q., Prakash, R., and Chaudhury, S. (2013). Infrequent near death experiences in severe brain injury survivors - A quantitative and qualitative study. Ann. Indian Acad. Neurol. 16, 75-81. doi: 10.4103/0972-2327.107715

Kelly, E. W. (2001). Near-death experiences with reports of meeting deceased people. Death Stud. 25, 229-249. doi: 10.1080/07481180125967

Klemenc-Ketis, Z., Kersnik, J., and Grmec, S. (2010). The effect of carbon dioxide on near-death experiences in out-of-hospital cardiac arrest survivors: a prospective observational study. Crit. Care 14, R56. doi: 10.1186/cc8952

Lai, C. F., Kao, T. W., Wu, M. S., Chiang, S. S., Chang, C. H., Lu, C. S., et al. (2007). Impact of near-death experiences on dialysis patients: a multicenter collaborative study. Am. J. Kidney Dis. 50, 124-132, 132 e121-122. doi: 10.1053/j.ajkd.2007.04.021

Lange, R., Greyson, B., and Houran, J. (2004). A Rasch scaling validation of a 'core' near-death experience. Br. J. Psychol. 95(Pt 2),161-177. doi: 10.1348/000712604773952403

Lempert, T., Bauer, M., and Schmidt, D. (1994). Syncope and near-death experience. Lancet 344, 829-830. doi: 10.1016/S0140-6736(94)92389-2

Lindley, J. H., Bryan, S., and Conley, B. (1981). Near-death experiences in a Pacific Northwest American population: the evergreen study. J. Near Death Stud. 1, 104-124.

Lopez, U., Forster, A., Annoni, J. M., Habre, W., and Iselin-Chaves, I. A. (2006). Near-death experience in a boy undergoing uneventful elective surgery under general anesthesia. Paediatr. Anaesth. 16, 85-88. doi: 10.1111/j.14609592.2005.01607.x

Martens, P. R. (1994). Near-death-experiences in out-of-hospital cardiac arrest survivors. Meaningful phenomena or just fantasy of death? Resuscitation 27, 171-175. doi: 10.1016/0300-9572(94)90010-8

McKay, R., and Cipolotti, L. (2007). Attributional style in a case of Cotard delusion. Conscious. Cog. 16, 349-359. doi: 10.1016/j.concog.2006.06.001

Mobbs, D., and Watt, C. (2011). There is nothing paranormal about near-death experiences: how neuroscience can explain seeing bright lights, meeting the dead, or being convinced you are one of them. Trends Cogn. Sci. 15, 447-449. doi: 10.1016/j.tics.2011.07.010

Moody, R. A. (1975). Life After Life. New York, NY: Bantam Press.

Nelson, K. R., Mattingly, M., Lee, S. A., and Schmitt, F. A. (2006). Does the arousal system contribute to near death experience? Neurology 66, 1003-1009. doi: 10.1212/01.wnl.0000204296.15607.37

Nelson, K. R., Mattingly, M., and Schmitt, F. A. (2007). Out-of-body experience and arousal. Neurology 68, 794-795. doi: 10.1212/01.wnl.0000256784.85952.6f

Osterman, J. E., Hopper, J., Heran, W. J., Keane, T. M., and van der Kolk, B. A. (2001). Awareness under anesthesia and the development of posttraumatic 
stress disorder. Gen. Hosp. Psychiatry 23, 198-204. doi: 10.1016/S01638343(01)00142-6

Owens, J. E., Cook, E. W., and Stevenson, I. (1990). Features of "near-death experience" in relation to whether or not patients were near death. Lancet 336, 1175-1177. doi: 10.1016/0140-6736(90)92780-L

Parnia, S., Waller, D. G., Yeates, R., and Fenwick, P. (2001). A qualitative and quantitative study of the incidence, features and aetiology of near death experiences in cardiac arrest survivors. Resuscitation 48, 149-156. doi: 10.1016/S03009572(00)00328-2

Posner, J. B., Saper, C. B., and Plum, F. (2007). Diagnosis of Stupor and Coma. New York, NY: Oxford University Press.

Ring, K. (1980). Life at Death: A Scientific Investigation of the Near-Death Experience. New York, NY: Coward McCann \& Geoghegan.

Ring, K. (1984). Heading Toward Omega: In Search of the Meaning of the Near-Death Experience. New York, NY: William Morrow.

Rodin, E. A. (1980). The reality of death experiences. A personal perspective. J. Nerv. Ment. Dis. 168, 259-263. doi: 10.1097/00005053-198005000-00001

Sabom, M. (1982). Recollections of Death: a Medical Investigation. New York, NY: Harper \& Row.

Schwaninger, J., Eisenberg, P., Schechtman, K., and Weiss, A. (2002). A prospective analysis of near-death experiences in cardiac arrest patients. J. Near Death Stud. 20, 215-232. doi: 10.1023/A:1015258818660

Stevenson, I., Cook, E., and McClean-Rice, N. (1989-1990). Are persons reporting "near-death experiences" really near death? A study of medical records. Omega $20,45-54$. van Lommel, P., van Wees, R., Meyers, V., and Elfferich, I. (2001). Neardeath experience in survivors of cardiac arrest: a prospective study in the Netherlands. Lancet 358, 2039-2045. doi: 10.1016/S0140-6736(01) 07100-8

Woerlee, G. M. (2005). Mortal Minds: the Biology of Near-Death Experiences. Amherst, NY: Prometheus Books.

Conflict of Interest Statement: The authors declare that the research was conducted in the absence of any commercial or financial relationships that could be construed as a potential conflict of interest.

Received: 31 January 2014; paper pending published: 11 March 2014; accepted: 23 March 2014; published online: 27 May 2014.

Citation: Charland-Verville V, Jourdan J-P, Thonnard M, Ledoux D, Donneau A-F, Quertemont E and Laureys $S$ (2014) Near-death experiences in non-life-threatening events and coma of different etiologies. Front. Hum. Neurosci. 8:203. doi: 10.3389/ fnhum.2014.00203

This article was submitted to the journal Frontiers in Human Neuroscience.

Copyright (C) 2014 Charland-Verville, Jourdan, Thonnard, Ledoux, Donneau, Quertemont and Laureys. This is an open-access article distributed under the terms of the Creative Commons Attribution License (CC BY). The use, distribution or reproduction in other forums is permitted, provided the original author(s) or licensor are credited and that the original publication in this journal is cited, in accordance with accepted academic practice. No use, distribution or reproduction is permitted which does not comply with these terms. 